ALVES, José Jerônimo de Alencar. A natureza e a cultura no compasso de um naturalista do século XIX: Wallace e a Amazônia. História, Ciências, Saúde Manguinhos, Rio de Janeiro, v.18, n.3, jul.-set. 2011, p.775-788.

\title{
A natureza e a cultura no compasso de um naturalista do século XIX: Wallace e a Amazônia
}

\section{Nature and culture in the eyes of a nineteenth-century naturalist: Wallace and the Amazon}

José Jerônimo de Alencar Alves

Pesquisador do Instituto de Educação Matemática e Científica/ Universidade Federal do Pará.

Rua Benjamin Constant, 724/1203

66053-040 - Belém - PA - Brasil

jeronimoalves@hotmail.com

Recebido para publicação em setembro de 2010

Aprovado para publicação em junho de 2011.

\section{Resumo}

A percepção de Alfred Russel Wallace sobre a região amazônica, a qual percorreu entre 1848 e 1852 , além de ser informada por seus conhecimentos sistemáticos, inclui juízos éticos e estéticos, como era comum entre os naturalistas. Os nativos da região seriam, para ele, pacíficos e hospitaleiros, mas também receptivos aos vícios da civilização. A natureza seria privilegiada, tanto para a atividade de história natural como para o prazer estético. Foram essas características que contribuíram para a permanência do naturalista na região e, portanto, para a realização de suas atividades científicas.

Palavras-chave: naturalistas viajantes; ciência; cultura; Alfred Russel Wallace (1823-1913); Brasil.

Abstract

Alfred Russel Wallace traveled through the Amazon from 1848 to 1852. His perceptions of the region were informed by his systematized knowledge but also influenced by judgments of an ethical and aesthetic nature, as was common among naturalists. He saw the region's 'natives' as peaceful and friendly but likewise susceptible to the vices of civilization. Nature afforded a privileged setting both for the activities of natural history and for aesthetic pleasures. These features helped keep the naturalist in the region, where he could thus engage in his scientific activities.

Keywords: traveling naturalists; science; culture; Alfred Russel Wallace (1823-1913); Brazil. 
abe-se que a ciência moderna se expandiu, desde seus primórdios na Europa do século XVII, para outras regiões do mundo. Alguns efeitos desta expansão são bem conhecidos. Transformaram acentuadamente as mentalidades, os hábitos, as técnicas, os valores, os modos de vida, ou seja, os diversos aspectos da cultura de outros povos que, gradativamente, passaram a adotar o modo de vida das sociedades científicas e tecnológicas. Os saberes locais dos gregos, babilônios, dos povos que habitavam a América Latina, enfim, dos povos em geral, passaram a ser envolvidos pela rede do novo saber que se espalhou pelo mundo e que passou a ser denominado ciência moderna ou ciências modernas, se se quer enfatizar que esse saber se divide em vários ramos, cada vez de forma mais acentuada (Polanco, 1989, p.10-21).

Essas mudanças, entretanto, não são apenas resultados de aplicações que ocorrem depois que as ciências se instalam. Acontecem desde o início, pois as leis e teorias científicas não existem nem se introduzem em uma cultura isoladamente; estão sempre associadas a interesses, valores, intenções e outros componentes que possibilitam sua recepção em determinado contexto cultural. A relação entre ciência e contexto social ou cultural tem sido bastante enfatizada pelos historiadores das ciências, embora cada um a apresente conforme seu ponto de vista e mediante diferentes conceitos, como, por exemplo, o de épistème, introduzido por Foucault (1986); o de paradigma, desenvolvido por Kuhn (1987); o de rede, criado por Latour (1994); ou de outra maneira; de qualquer modo, porém, ela passou a ser admitida, cada vez mais, a partir da segunda metade do século passado.

As teorias científicas estão sempre circunscritas por uma 'visão de mundo', por sua vez associada a valores, intenções, preceitos morais e sentimentos estéticos, ou seja, o éthos de uma cultura (Geertz, 1989, p.143-162). Todos esses fatores são determinantes para que uma teoria, durante certo tempo, tenha lugar proeminente na ordem dos discursos científicos. A história está repleta de exemplos: a teoria da seleção natural das espécies emergiu associada ao desejo de deslocar a ideia da criação divina do mundo; as explicações da microbiologia sobre os determinantes da febre amarela surgiram com a intenção de combater as epidemias que impediam a colonização; as teorias sobre a fissão nuclear ganharam impulso motivadas pelo anseio de construir a bomba atômica na Segunda Guerra Mundial.

Como quaisquer outras modalidades de saber, também as chamadas ciências puras só existem associadas a valores que circulam no ambiente cultural em que se inserem, ainda que esses valores não sejam explicitados. ${ }^{1}$

Para angariar apoio às ciências puras, na virada do século XIX para o XX, alardeava-se que elas aprimoravam os valores éticos e estéticos daqueles que a praticavam. Nos dias de hoje, permanece a ideia de que, mesmo sem estarem atreladas a fins utilitários, elas acabam sendo assim utilizadas, indireta ou diretamente. No primeiro caso, porque serviriam de base para as ciências aplicadas; no segundo, porque no futuro encontrariam aplicações diretas, como traduz a metáfora "à flor sucedem os frutos", enunciada pelo presidente da Academia Brasileira de Ciências, na entrada no século XX (Alves, 1991, p.117).

De qualquer modo, as atividades voltadas para a produção de teorias científicas, mesmo que não estejam dirigidas diretamente a projetos materiais ou utilitários, sempre se encontram associadas a interesses, valores e fins que, em última instância, são considerados úteis àqueles que as cultivam. Todos esses fatores que se difundem junto com os conhecimentos 
científicos interagem com aqueles que fazem parte da visão de mundo ou do éthos da cultura em que se inserem. Nessa interação, esses fatores são modificados. Portanto, as teorias científicas, no novo contexto, não são sustentadas por valores, aplicações e finalidades idênticos aos que as sustentaram na cultura de origem. Em determinado contexto cultural, um campo teórico pode ser valorizado e dirigido para a produção de medicamentos, em outro, para a produção de artefatos bélicos. Pode, também, não produzir qualquer resultado material e ser valorizado, sobretudo, como símbolo de progresso e modernização, mesmo que as promessas materiais estejam presentes nos discursos destinados a promovê-lo.

As relações que se estabelecem no processo de interação científica não são simétricas. Elas possuem hierarquia, pois, embora apoiadas na concepção de que todos devem colaborar para a renovação de conhecimentos, alguns centros têm mais poder, tanto de obter legitimidade científica para os conhecimentos que produzem como de os difundir para os demais. Por outro lado, as teorias surgem em determinado contexto social pela dinâmica dos valores, desejos, enfim, pela visão de mundo que se desdobra em seu próprio interior. Nos contextos de recepção, vindas de fora, as teorias chocam-se com a visão de mundo preexistente. Absorver, pelo menos em parte, a visão de mundo que se impõe a partir do exterior é condição necessária para a recepção das teorias científicas que chegam.

Pretendo contribuir para compreender a relação entre as atividades científicas e os valores que motivam essas atividades, acompanhando a incursão do naturalista Alfred Russel Wallace (1823-1913) à Amazônia, região em que permaneceu de 1848 a 1852. Tendo vindo com Henry Bates (1825-1892), também naturalista, após pesquisarem durante quase um ano no Pará - na área em que hoje se situa a cidade de Belém e regiões próximas, como as que ficam às margens do rio Tocantins -, resolveram separar-se, pois assim suas pesquisas teriam alcance maior. Bates viajou pela região do Caripi, situada na foz do rio Amazonas, que depois subiu, seguindo até o Solimões. Wallace, após viajar pelo Marajó, subiu o Amazonas e enveredou pelo rio Negro.

Os naturalistas se depararam com região drasticamente diferente de seu lugar de procedência no que se refere à natureza e à cultura. A cidade do Pará (hoje Belém), a mais urbanizada da região amazônica, é descrita por Bates $(1979$, p.14) como "uma clareira aberta na mata". A maior parte dos 15 mil habitantes que viviam na cidade era constituída por índios, negros e mestiços. A elite local, entretanto, formava-se, principalmente, de europeus e seus descendentes, e atuava como comerciantes (na maioria portugueses), fazendeiros, membros do clero e capitães de província. As instituições voltadas para a educação restringiam-se às escolas primárias e a um seminário.

Wallace exerceu atividades científicas nessa região, antes (embora às vésperas) da ascensão do paradigma darwinista, e, como se sabe, contribuiu para a emergência desse paradigma. Suas ideias sobre a seleção natural culminaram com a famosa comunicação apresentada na Linnean Society of London em 1858 como de sua autoria juntamente com Darwin. Pelo impacto que essa questão imprimiu na trajetória do conhecimento científico, as reflexões historiográficas sobre as atividades científicas de Wallace incidem em grande parte sobre ela, como a de Ferreira (1990).

O objetivo do presente artigo, entretanto, é outro. Não é indagar como as atividades desse naturalista contribuíram para a seleção natural, mas analisar sua interação com a 
natureza e a cultura da região amazônica, como objeto de investigação científica e como fonte de conforto e prazer estético.

Trata-se de resgatar essa percepção através de seus próprios escritos para saber quais os objetos, as questões, os valores que ele enfatizou ao descrever a Amazônia. Como sugere Foucault ${ }^{2}$, não se trata de procurar os conhecimentos que teriam progredido na direção de uma objetividade reconhecida pela ciência dos dias atuais e, sim, as formas de saber que encontraram condições de emergir naquele momento.

Para essa abordagem, foram fundamentais os textos escritos pelo próprio naturalista, que se encontram reunidos no site The Alfred Russel Wallace Page, e seu livro Viagens pelos rios Amazonas e Negro (Wallace, 1979), denso de passagens em que a suas descrições mais sistemáticas são intercalados sentimentos e valores.

A percepção das regiões tropicais pelos viajantes, os naturalistas incluídos, tem sido objeto de análise de alguns autores, como Roberto Ventura que, em seu livro Estilo tropical (1991), remonta à percepção da América pelos europeus. Ele aponta que a colonização da América pelos europeus foi presidida pela 'visão do paraíso', posteriormente invertida pelos filósofos do século XVIII, como Cornelius de Pauw, Raynal e outros, que perceberam o clima tropical como agente de degeneração, contribuindo, assim, para legitimar a expansão colonial europeia, que pretendia difundir as 'luzes da Europa civilizada'. O naturalista Alexander von Humboldt resgatou a imagem original, pois, em vez de seres degenerados, via nos trópicos seres robustos e sadios. Ventura (1991, p.22) afirma: "O homem selvagem e a natureza americana são percebidos de forma ambivalente pelo discurso europeu, que oscila entre a imagem positiva da felicidade natural e inocente dos habitantes de clima fértil, e a condenação de seus costumes bárbaros".

A abordagem humboldtiana propagou-se entre os naturalistas, como se constata nas obras de von Martius, Saint-Hilaire e outros. Suas descrições sistemáticas e precisas sobre as regiões visitadas eram acompanhadas de impressões sensíveis, tais como sentimentos éticos e estéticos. Homem e natureza apresentam-se estreitamente relacionados nas concepções de Humboldt e dos que o seguiram (Kury, 2001). A obra de Wallace não poderia deixar de ser marcada por esse estilo de abordagem que ainda permanecia em vigor quando ele esteve na Amazônia, antes, como lembrado, da expansão do paradigma darwinista.

Em 1866, um grupo de ilustrados paraenses fundou uma sociedade filomática com a finalidade principal de criar um museu de história natural e etnografia. O resultado é o atual Museu Paraense Emílio Goeldi, que se tornou ponta de lança do processo de inserção das ciências modernas na região. Isso significa que esse campo do conhecimento científico já era então valorizado na região. O museu original resultou desse processo de valorização que se veio gestando no contato dos habitantes locais com a cultura do 'mundo moderno', em parte pela presença dos naturalistas na região. De certo modo, a estada de Wallace contribuiu para a valorização regional da história natural, embora não diretamente para a criação do Museu Paraense, que lhe é posterior (Alves, 2004; Sanjad, 2010; Crispino, 2006).

A escolha de um naturalista e de sua ciência, para a presente reflexão, foi estimulada pela emergência da temática sobre o meio ambiente nos dias de hoje. A representação da natureza como objeto de contemplação ou de prazer no discurso dos naturalistas está mais próxima das questões atuais sobre o meio ambiente do que daquelas pertencentes aos 
campos da física, da química e outras ciências contemporâneas. Conhecer a percepção que tinham os naturalistas de animais, plantas e outros objetos da história natural é importante, pois ela serve de contraponto para se compreender a que hoje se tem do meio ambiente.

Para analisar a percepção da Amazônia por Wallace, em primeiro lugar serão resgatados seus juízos científicos e estéticos a respeito de animais e plantas e, ainda, dos habitantes da região, analisando nesse caso também seus juízos éticos.

\section{Animais e plantas sob o olhar científico e estético de Wallace}

Como os demais naturalistas, Wallace vinha coletar os seres da floresta, porque considerava que seu estudo era importante para elucidar questões da história natural. Por que, entretanto, teria escolhido essa e não outra região do mundo para permanecer durante quatro anos? Teriam sido apenas científicos os motivos que o mobilizaram para atravessar o oceano e enfrentar inúmeras dificuldades de adaptação em uma natureza drasticamente diferente daquela de sua procedência? Haveria outros?

Uma primeira razão para deslocar-se até a Amazônia era a imagem que tinha dos trópicos, inspirada, sobretudo, nos relatos de viajantes - como A voyage up the river Amazon (Uma viagem subindo o rio Amazonas), de William Edwards, publicado em 1847 -, já que suas excursões anteriores limitavam-se ao continente europeu. Essas imagens o faziam acreditar que, ali, sob a grandeza da floresta, vivia uma variedade enorme de seres cujo conhecimento seria de grande importância para o avanço da história natural. O desejo de conhecer os trópicos era científico e ao mesmo tempo estético, pois imaginava que nada existiria sob o sol tropical que não fosse diferente do resto do mundo e, mais do que isso, extraordinário, fantástico e maravilhoso. Queria "ver com meus próprios olhos todas as maravilhas, cujo conhecimento, através da leitura das narrativas dos viajantes, tanto me deleitava" (Wallace, 1979, p.11). Mas por que a Amazônia em detrimento de outras regiões tropicais?

Alguns motivos para essa escolha, ele mesmo aponta em Viagens pelos rios Amazonas e Negro (Wallace, 1979, p.11): o menor conhecimento que se tinha sobre essa região em relação a outras do continente sul-americano; as dificuldades de acesso à Amazônia, que lhe pareciam menores em comparação com as rotas para outras regiões de seu interesse; e a influência de suas leituras anteriores.

Quando Wallace chegou à região amazônica, a paisagem que se descortinava a seus olhos parecia não corresponder à que suas leituras tinham inspirado. A variedade dos seres não parecia tão extraordinária nem tão fantástica como imaginara, nem os insetos tão numerosos, embora as abelhas, vespas e borboletas fossem abundantes; as árvores não se afiguravam tão diferentes, ainda que nelas percebesse "numerosas peculiaridades tropicais" (Wallace, 1979, p.21). É claro, que, sendo assim, apesar de continuar a admitir a importância dos seres para sua pesquisa, a abundância desses seres não correspondia a suas expectativas.

A imagem preconcebida também se modificava em outros aspectos. O clima não lhe parecia tão quente, as pessoas não eram tão diferentes, nem a vegetação tão extraordinária. Nada coincidia com a fantástica imagem do belo cenário paisagístico que até então acalentara. Ele admitia a presença da beleza, mas não generalizada e, sim, localizada em certos nichos da natureza. Constatava, por exemplo, não haver nenhum exagero em suas 
expectativas sobre as palmeiras, que, pela elegância de suas formas e a beleza de suas folhagens, seriam de enorme interesse para o naturalista (Wallace, 1979, p.18-21).

Assim, a fantástica imagem que Wallace absorvera nos relatos sobre a região se desfazia no contato direto com a natureza. Desencantava-se, porém acreditava que essa sensação pudesse ser provisória e, portanto, plena de subjetividade: "a sensação de prazer que sentimos ao contemplar uma obra da Natureza depende, em grande parte, das associações de ideias que possamos relacionar com a sua utilização e o seu caráter de novidade ou com sua história" (Wallace, 1979, p.272). Afirma, ainda, que "os encantos de uma região vão-se revelando, pouco a pouco, à medida que contemplamos as diversas partes que a compõe e à proporção que nossa educação e nossos hábitos nos permitem compreendê-los e admirálos" (p.18).

O naturalista, portanto, estava predisposto a rever seu desencanto inicial sobre a natureza amazônica e a observá-la através de lente mais positiva. As mudanças derivadas dessa predisposição podem ser constatadas no decorrer de seu relato, em que o pleno otimismo retorna, tanto no que se refere à variedade e à potencialidade das espécies animais e vegetais quanto em relação a sua estética. Alusões à beleza dos seres da floresta estão presentes ao longo de seu livro de viagem, mesmo nos capítulos mais especificamente destinados à história natural.

No que se refere à potencialidade da região para os estudos da fauna e da flora, suas descrições são pontilhadas de expressões sobre a grandeza e a variedade dos seres que a habitam. Assim, considera que a abundância de peixes deve ser proporcional ao lugar em que vivem, ou seja, a maior bacia hidrográfica do mundo. Sua impressão em relação aos répteis não é menos vívida, esses seriam, além de abundantes, enormes e singularíssimos. A vegetação também seria insuperável. Em relação aos mamíferos, porém, supõe que não superam nem sequer se igualam, em tamanho e variedade, aos que existem em certas regiões do globo (Wallace, 1979, p.275-285).

Foi com esse entusiasmo em relação à grandeza e à variedade dos seres amazônicos que Wallace passou a descrevê-los. Aos capítulos em que relata suas experiências de modo mais cronológico e generalizado, seguem cinco dirigidos mais especificamente aos campos científicos em vigor na pauta dos naturalistas: geografia física e geologia, vegetação, zoologia, aborígenes e gravuras rupestres.

Wallace embrenhou-se na Amazônia, com a intenção de contribuir com as ciências dos naturalistas, que vinham colocando questões há mais de um século, muitas persistindo sem respostas, pois tratavam de descrever e classificar os seres da natureza, e grande parte deles ainda era desconhecida. Para tanto, descrevia-lhes a aparência física exterior, a dinâmica de alimentação e reprodução, e os modos de capturá-los. Suas descrições eram predominantemente sincrônicas. Embora existisse a preocupação com a evolução dos seres no tempo, nem o tempo nem a evolução tinham o destaque absoluto que alcançaram no decorrer da segunda metade do século XIX, em que a polêmica sobre a origem das espécies ocupou o lugar principal dos debates científicos.

O efeito do tempo na transformação dos seres ainda não era o centro dos debates na história natural ${ }^{3}$, mas isso não significa que essa questão estivesse ausente. Embora não disseminada ao longo de todo o livro, está presente, por exemplo, quando ele aborda a 
época da formação das camadas geológicas da Terra e quando trata da distribuição geográfica dos animais. É então que Wallace se interroga sobre a possibilidade de mistura dos animais no decorrer do tempo, supondo que as espécies tenham sido distintas desde a origem e considerando que certas barreiras como rios e oceanos são intransponíveis para algumas (Wallace, 1979, p.287).

Suas descrições da natureza são permeadas de apreciações estéticas, e nesse sentido seu entusiasmo é acentuado. Em sua opinião, os insetos não eram apenas mais variados do que em qualquer região do mundo, eram também mais belos, e as aves eram "tão numerosas e notáveis que, neste volume, outra coisa não podemos fazer, senão limitar-nos a mencionar algumas das mais belas e interessantes" (Wallace, 1979, p.282). Ele chega a afirmar que "não há no mundo um lugar como este, para fazer uma bela coleção de aves e outros animais" (p.192).

Enfim, o desencanto de sua primeira impressão foi gradativamente recoberto por nova imagem cuja beleza se ampliou, tanto nas aves e nos insetos como nos diversos recantos da paisagem. Imagens que não se reduzem à descrição dos componentes da floresta, conforme a pura intenção de objetividade científica, sendo pontilhadas de deleite estético:

Ao pôr do sol, deparamos com uma cena maravilhosa: Grupos de elegantes palmeiras e enormes paineiras destacavam-se contra o céu cor de ouro. As casas dos negros, rodeadas de laranjeiras e mangueiras; as margens relvosas, o rio solene e, ao fundo, a onipresente floresta, tudo suavizado pela branda luminosidade daquela mágica meia hora crepuscular, compunham uma paisagem de indescritível beleza (Wallace, 1979, p.46).

Seu balanço sobre a estética da paisagem amazônica tende para o lado positivo. Ao avaliá-la, ele a equipara às paisagens europeias que tem como belas, guardadas as especificidades:

Acredito que os panoramas de nossa própria terra dentro de seu gênero sejam de fato insuperáveis. Não há, nos trópicos, um que os possa igualar, assim como os cenários tropicais também não podem ser encontrados em nossa terra. Ali, as características mais notáveis são os troncos de formatos singulares, os curiosos cipós, as gigantescas folhas, as elegantes palmeiras e as plantas isoladas com suas magníficas folhas. Já, aqui, são as infindáveis extensões recobertas de ervas verdes em meio às quais sobressaem compactos grupos de flores alegres e coloridas; são as variegadas tonalidades das folhagens, são as alternadas ocorrências de campinas e florestas, de prados e bosques, que mais que os indivíduos isolados, enchem o observador de encanto e prazer (Wallace, 1979, p.273).

\section{Os habitantes da região sob o olhar científico, ético e estético do naturalista}

Wallace inclui os nativos em seus estudos como era praxe entre os naturalistas.Em descrições bastante amplas, focaliza desde a indumentária até os hábitos alimentares, as formas de guerrear e a receptividade ao estrangeiro. ${ }^{4}$ A possível origem comum das tribos da Amazônia e da África (que o naturalista só conhecia por meio de estudos teóricos e outros relatos) é questão presente em suas interrogações. Embora acreditasse ter encontrado fortes semelhanças entre essas tribos, os dados então disponíveis eram ainda insuficientes para precisar se essas semelhanças eram devidas a uma pretérita conexão entre elas, ao fato 
de estarem submetidas a idênticas condições climáticas ou porque estivessem em "um estágio incipiente de civilização" (Wallace, 1979, p.313).

Quanto às impressões estéticas sobre o corpo dos índios, o naturalista apresenta menos dúvidas e alcança o deleite quando o considera esteticamente superior ao de qualquer europeu e mais fascinante do que qualquer obra de arte:

Podem estar certos de que considero esses perfeitos exemplares da maravilhosa anatomia humana, mais fascinantes e admiráveis do que a mais bela estátua esculpida pelo homem. Sua impressionante musculatura torácica não é igualada pela de nenhum europeu que conheço, consistindo seu tronco numa esplêndida sequência de ondulações convexas, sem a mínima concavidade ou flacidez (Wallace, 1979, p.292).

Seu entusiasmo vai além dos corpos e chega aos movimentos quando ele descreve as danças, os rituais e outras manifestações coletivas, sem excluir juízos de valor e expressando os efeitos que produzem em seus sentidos. É desse modo que ele manifesta seu sentimento de júbilo por presenciar um ritual que descreve como um espetáculo exótico, pitoresco e belo. Não se trata de um neutro observador, mas de um ser sensibilizado pela vibração que emana daquele cenário.

O selvagem e o estranho aspecto desses índios de belo porte, despidos e pintados, com seus curiosos enfeites e armas, o bater dos pés e o chocalhar dos frutos secos, acompanhando a música e a dança, o zumzum das conversas numa língua tão estranha; a música dos pífaros, das flautas grandes e de outros instrumentos feitos de bambu, osso, carapaça de tartaruga; as grandes cabaças de caxiri que eram constantemente trazidas aos participantes, e a enorme cabana escura, enegrecida pela fumaça, produziam um efeito literalmente indescritível, do qual a visão de meia dúzia de índios exibindo-se num palco dá-nos apenas uma ideia muito pálida (Wallace, 1979 , p.179). ${ }^{5}$

Com relação ao comportamento dos habitantes da região, bem como a seus princípios éticos, os juízos do naturalista são mais complexos. Há nítida diferença em seus julgamentos que se referem aos costumes tradicionais dos nativos e a seus hábitos posteriores ao contato com a civilização. Por outro lado, seus julgamentos se modificaram, pelo menos em parte, ao longo de sua permanência na região.

Sua primeira impressão ao chegar ao Pará, então habitado por mescla de índios, negros e brancos, não foi das mais favoráveis. O panorama que via parecia-lhe associado à sujeira e à desordem, que por sua vez seriam evidências de apatia e indolência. Essa primeira impressão, entretanto, logo desapareceu ao constatar que "os amplos e altos cômodos, com pisos de tábua, e meia dúzia de portas e janelas" eram absolutamente adequados à região tropical, "na qual seriam insuportáveis quartos cheios de tapetes, cortinas e almofadas" (Wallace, 1979, p.20).

Suas avaliações posteriores, quando incidem sobre os costumes tradicionais dos nativos, dificilmente são negativas, mesmo quando se referem aos que lhe parecem bastante exóticos. Assim, não há qualquer censura ao intenso consumo do caxiri nas longas festividades, ao costume da poligamia e mesmo às chibatadas suportadas pelas meninas no ritual da puberdade. Por outro lado, suas expressões são de admiração, ao considerar o "grau de sociabilidade e mútua convivência que caracterizava aquelas inúmeras famílias vivendo juntas em harmonia patriarcal" (Wallace, 1979, p.178). Nas expressões mais entusiasmadas 
ele chega a afirmar que as "boas qualidades são características dos nativos 'não civilizados'" (Berry, 2003, p.170; tradução livre).

Com relação ao comportamento dos nativos aculturados, entretanto, suas opiniões são mais complexas. As descrições desses comportamentos às vezes são críticas, mas muitas vezes de aprovação, como na citação que segue, que os apresenta como laboriosos e receptivos à educação e, portanto, portadores de comportamentos valorizados no mundo civilizado.

Muito raramente ocorrem altercações entre eles. São laboriosos e submetem-se de bom grado à autoridade. Nas tarefas que realizam, demonstram engenho e habilidade. Adotam fácil e rapidamente os costumes civilizados com os quais entram em contato, parecendo perfeitamente capazes de se transformarem, através da educação bem orientada, numa comunidade pacífica e civilizada (Wallace, 1979, p.314)

Em sua opinião, entretanto, essa transformação parece de difícil concretização, pois, em vez de à educação bem orientada, os nativos são expostos aos vícios da civilização - três seriam os mais disseminados pelos colonizadores, na província do Pará: bebida, jogo e mentira. Esta última também sob a forma de trapaça, permearia as práticas comerciais, em que todos procurariam ludibriar o comprador e arruinar os concorrentes. Um dos fatores responsáveis pela introdução dessas imoralidades seria a aversão inata dos colonizadores ao trabalho mecânico e à agricultura; além disso, seu espírito aventureiro os induziria a penetrar as regiões selvagens em busca de facilidades mercantis sem resquícios de civilidade.

O clima tropical colaboraria para a adoção desses vícios, posto que ofereceria menos opções de lazer, prazer e ocupação do que o clima temperado. Para corroborar essa afirmação, o naturalista apresenta uma série de argumentos. O calor do estio e a umidade do inverno não favoreceriam jogos e exercícios ao ar livre. A ausência de longas e frias noites hibernais não promoveria o intercâmbio social e familiar, em torno da lareira. A natureza seria desprovida de paisagens que pudessem seduzir "o amante da natureza" (Wallace, 1979, p.235).

Essas alusões negativas à natureza e ao clima contradizem, no entanto, inúmeras descrições em que ele considera a natureza fonte de deleite e o clima tropical, agente favorável ao trabalho, chegando de fato a afirmar que "em lugar nenhum do mundo o trabalhador encontra um clima e uma natureza tão favoráveis a seus propósitos" (Wallace, 1979, p.209; Alves, 2008). Reiteradamente os habitantes da região são caracterizados como laboriosos ao extremo:

As pessoas daqui trabalham quase todo o tempo, entretanto nada têm. As mulheres estão sempre escavando mandioca e inhames, ou então arrancando ervas daninhas ou cuidando das plantações, ou fazendo vasilhas de barro, ou lavando e remendando suas roupas. Os homens, também, não deixam por menos, quando não estão roçando a floresta, estão derrubando uma árvore para fazer canoa, os remos, ou tábuas (Wallace, 1979, p.113)

Para compreender a contradição em seu julgamento sobre a relação entre clima e capacidade de trabalho, convém lembrar que as considerações de Wallace sobre o comportamento dos nativos fundamentavam-se tanto em suas observações empíricas como nas teorias já aprendidas, e, entre essas ideias, havia as que apontavam o clima tropical 
como agente de degeneração e as que se contrapunham a esse pessimismo, como as de Humboldt e seus seguidores (Ventura, 1991, p.27).

Constata-se, contudo, que seus juízos negativos a respeito da ética e dos costumes locais incidem mais sobre a população aculturada do que sobre a tradição indígena, em relação a qual suas mais frequentes impressões são positivas. Negativa, em sua opinião, é a contaminação da tradição dos nativos pela cultura dos colonizadores. Apesar de admitir que o único caminho possível para os nativos seja o da civilização e que eles sejam perfeitamente capazes de se transformar, pela educação, em uma comunidade pacífica e civilizada, esse caminho lhe parece bastante sombrio, uma vez que os indígenas estariam expostos à influência da escória da sociedade brasileira, sendo mais provável que, com o passar dos anos, ficassem reduzidos à condição dos índios semicivilizados do país, que parecem ter perdido as boas qualidades da vida selvagem e adquirido apenas os vícios da civilização (Wallace, 1979, p.314).

\section{A percepção do naturalista sobre sua recepção}

Wallace era proveniente da Europa, de onde viera parte daqueles que detinham o poder econômico e a influência política na região amazônica. Mais especificamente, procedia da Inglaterra, um dos países europeus de maior poder econômico e domínio científico na época. O apoio que recebeu dos habitantes da região, promovendo as condições para suas práticas científicas, é apontado ao longo de seu relato de viagem. Ele e Henry Bates foram convidados a permanecer na residência do consignatário do navio em que vieram da Europa que posteriormente lhes cedeu sua rocinha. ${ }^{6}$ A partir desse primeiro contato, os naturalistas passaram a ser apresentados aos fazendeiros, comerciantes e representantes do poder local, em parte europeus e americanos (Wallace, 1979, p.18).

O cônsul da Suíça no Pará colocou suas terras à disposição dos naturalistas e os orientava sobre as trilhas da floresta mais favoráveis a seus objetivos. O senhor Leavens, engenheiro americano e administrador de uma fazenda, que os recebia com extrema amabilidade, possuía grande interesse pela história natural. Wallace informa que ele colecionava pássaros, que empalhava "com extrema habilidade", e fazia questão de acompanhar os naturalistas em suas excursões pela floresta, indicando-lhes como encontrar os animais que buscavam, enfim, tentando ajudá-los com seus conhecimentos. Acompanhou-os, aliás, na viagem pelo rio Tocantins, sem dúvida, estimulado pelo desejo de participar daquela aventura científica, embora seu objetivo principal fosse encontrar madeiras de valor econômico (Wallace, 1979, p.31).

Nesses primeiros contatos, os naturalistas receberam cartas de apresentação dirigidas às pessoas de poder político e econômico dos mais distantes povoados da Amazônia. Embora a ciência não fizesse parte da cultura desses povoados, que de hábito não possuíam qualquer escolaridade formal, pelo menos suas minorias, detentoras do poder político e econômico, valorizavam o saber, como sugere carta de recomendação a um comandante de distrito, solicitando proteção e hospitalidade para os viajantes, "devotados às ciências e cujo alimento é a própria História Natural em si" (Wallace, 1979, p.50). 
Revestidos da identidade de legítimos representantes da ciência e da civilização, os naturalistas eram recebidos cordialmente por comerciantes, fazendeiros, juízes, comandantes de distritos e outros componentes das elites locais, que quase sempre colocavam gratuitamente a sua disposição alimentos, residência, embarcação e mão de obra. As condições que recebiam para suas atividades científicas vinham mais da iniciativa privada, derivada das relações patriarcais, do que da esfera pública.

Wallace reconhecia a boa recepção das elites locais, mas, mesmo assim, queixava-se: as cartas de apresentação não tinham a eficácia que desejava no sentido de obter a mão de obra de que necessitava. Encontrava regular dificuldade em conseguir quem conduzisse as canoas, tarefa realizada pelos índios que resistiam a submeter-se à ordem colonizadora.

Membros da população local eram empregados nos afazeres domésticos, na coleta dos seres da floresta e em função do saber que detinham sobre a região. O velho guia Isidoro estava "a par, não só do nome de todas as árvores, como também de suas propriedades e seus empregos", Wallace informa, "o fato é que ele gostava de exibir seus conhecimentos sobre esses assuntos dos quais ainda nos encontrávamos no estágio da mais completa ignorância, mas cuja aprendizagem queríamos realmente alcançar" (Wallace, 1979, p.50).

Por outro lado, os nativos também tinham interesse em apreender a visão de mundo do naturalista. A curiosidade por esse mundo e a dificuldade de compreendê-lo são bem expressas nos comentários que ouvia daqueles que ficavam horas a fio acompanhando suas práticas científicas com "interesse verdadeiramente infatigável".

\footnotetext{
"Ah, esses brancos, que paciência!". Aí, um cochichava para o outro: "será que ele tira toda a carne?!". Seguia-se uma rápida discussão sobre a finalidade daqueles trabalhos. Para que serviriam? "Para mostrar", era a solução geralmente encontrada por alguém. Mas a maioria não concordava, julgando insatisfatória aquela explicação. Não, os ingleses por certo não seriam tão malucos a ponto de apreciar a mera contemplação de peles recheadas, de pombos e papagaios... Já para as borboletas, alguém sugeriu uma explicação que a todos pareceu satisfatória, dizendo que deveriam servir para obter novas padronagens de tecidos e estampados, ou qualquer coisa semelhante. E, quanto aos feiosos insetos, supunham que serviam para fazer remédios (Wallace, 1979, p.51).
}

A suposição de que aqueles objetos seriam utilizados para novos padrões de tecidos ou confecção de remédios estava em conformidade com as práticas culturais dos nativos, pois eram modos como utilizavam os seres da floresta. Quanto ao empalhamento dos animais, sua finalidade lhes era menos compreensível, por ser algo completamente distinto de suas práticas culturais. Seria necessário perceber os valores que sustentavam a ciência do naturalista e, portanto outra cultura, para poder compreender aquela atividade. Para adotála, seria necessário, aliás, que adotassem esses valores. Assim, os nativos teriam que modificar sua relação com a natureza, interrogando-a não apenas sobre seus possíveis perigos e utilidades ou sobre as divindades que acreditam habitá-la, mas também conforme os ditames da história natural, para saber, por exemplo, até que ponto os seres da natureza teriam origem comum, mesmo que para isso tivessem que se debruçar ao longo dos anos à incessante tentativa de classificar sistematicamente todos os seres conforme a ordem ditada por esse campo do conhecimento (Foucault, 1987, p.10). 


\section{Considerações finais}

As descrições feitas por Wallace da natureza amazônica são permeadas de juízos estéticos, o que não era incomum entre os naturalistas; entretanto, além de ter plena consciência da subjetividade desses juízos, ele admite ser possível agir sobre eles. Dispõe-se a mudar a reação negativa do primeiro encontro com a região, por não ter correspondido à imagem preconcebida a partir dos relatos dos viajantes e naturalistas, que indicavam ser tudo completamente novo e maravilhoso. Admitindo que essa primeira impressão mais se devesse à percepção de seu olhar estrangeiro do que à natureza em si, ele se refez do desencanto inicial e buscou encontrar nela elementos para ancorar uma imagem otimista e plena de entusiasmo.

Assim, volta a admitir o caráter extremamente promissor da natureza amazônica para seus estudos científicos, percebendo-lhe maior variedade de animais do que em qualquer outro lugar do mundo, com exceção dos mamíferos. Essa natureza, por seus grandes rios e outros acidentes que serviam de barreira à circulação das espécies, lhe parecia propícia para compreender o capítulo que considerava o mais importante de sua área de conhecimento, aquele referente à distribuição geográfica dos animais, tema que passaria a dominar os cânones da história natural nas décadas seguintes.

A natureza amazônica também é valorizada no sentido estético, predominando em suas descrições as imagens positivas. Animais e plantas são considerados de rara beleza; os corpos dos índios, descritos com tal entusiasmo, que chegam a ser comparados com obras de arte. Isso não significa que o naturalista considerasse todos os recantos da paisagem selvagem esteticamente superiores aos de seu lugar de origem, mas, no mínimo, rivalizavam com eles. Se a floresta amazônica não era tão florida como os prados da Europa, era majestosa. Sua percepção da natureza amazônica, entretanto, nem sempre tem caráter superlativo. Alguns recantos são considerados monótonos, mas ele nunca os descreve com alusões extremamente depreciativas, como fizeram alguns viajantes.

Com relação aos costumes dos nativos suas impressões diferem conforme sejam eles aculturados ou não; dificilmente são negativas ao tratar dos costumes dos nativos não aculturados, que seriam marcados pelo pacifismo, pela harmonia tribal e por outras características favoráveis. Quando se refere aos costumes nativos aculturados, no entanto, suas conclusões não são tão positivas. Podem ser negativas e, às vezes, beiram a ambiguidade.

São negativas, por exemplo, quando considera que, embora eles tenham capacidade de adquirir os valores positivos da civilização, na prática, isso não acontece, pois seu contato tem sido com a escória da civilização, através da qual absorvem os vícios e os maus costumes. São positivas quando, ao relatar sua recepção pelos habitantes locais, enfatiza-lhes a generosidade, a hospitalidade e a cordialidade. São, enfim, ambíguas, quando afirma que os nativos são pouco laboriosos, mesmo tendo registrado o contrário em outras ocasiões.

Wallace veio à Amazônia pelo interesse científico, mas também pelo desejo de conhecer uma natureza exótica e conforme à imagem que construíra através de leituras. Realizado esse desejo, ele passou a oscilar, durante sua permanência na região, entre duas posições: uma que o conduzia à sua origem, lugar pleno de afeto e enaltecido pela distância; outra que o convidava a permanecer em um mundo primitivo, livre de preocupações financeiras 
e aborrecimentos da civilização; mundo que, nos momentos de maior deleite, lhe parecia um reino de tranquilidade, fartura e paz. Essa última imagem, sem dúvida, contribuiu para que ele aqui permanecesse quatro anos realizando atividades científicas. Regressou à Europa em 1852 e em 1854 já se encontrava nas Índias Orientais, ou seja, em outro 'mundo primitivo', no qual se demoraria oito anos.

\section{NOTAS}

${ }^{1}$ Segundo Bourdieu (1997, p.30), a ideia de desinteresse, nas 'ciências puras', não exclui o interesse, pois o jogo científico é sempre realizado por algum motivo. Por outro lado, Pestre (1985, p.173-180) mostra que na França, entre as duas guerras mundiais, a ciência pura era considerada produtora de virtude; Alves (1991) informa que ciência também era assim considerada na Academia Brasileira de Ciências.

${ }^{2}$ Essa premissa é assinalada de várias maneiras em seus textos. Em sua opinião é improcedente considerar os conhecimentos progredindo "em direção a uma objetividade na qual a nossa ciência, hoje, pudesse enfim, se reconhecer" (Foucault, 1987, p.11). Sua intenção é trazer para a luz o campo epistemológico, "onde os conhecimentos encarados fora de qualquer critério referente ao seu valor racional ou às suas formas objetivas enraízam sua positividade" (p.11).

${ }^{3}$ Sobre a irrupção do tempo no espaço da história natural, ver Foucault, 1987.

${ }^{4}$ Os estudos dos naturalistas eram menos especializados do que aqueles dos demais campos da ciência moderna, com exceção dos antropológicos. Com relação a estes últimos, ver Latour, 1994, p.20.

${ }^{5}$ Caxiri é uma bebida fermentada à base de mandioca, que provoca alteração dos sentidos, utilizada nos rituais indígenas e à qual os índios atribuem acesso ao mundo sobrenatural.

${ }^{6}$ Nome dado às residências afastadas do centro da cidade, geralmente amplas, arborizadas.

\section{REFERÊNCIAS}

ALVES, Ana Maria Alencar.

Redutos da ciência na 'era dos museus': Inglaterra, França, Estados Unidos e Brasil. Tese (Doutorado) - Faculdade de Filosofia, Letras e Ciências Humanas, Universidade de São Paulo, São Paulo. 2004.

ALVES, J. Jerônimo de Alencar.

Determinismo climático e salubridade na Amazônia na percepção de Bates e Wallace. Cadernos de História da Ciência, São Paulo, v.4, n.2, p.37-49. 2008.

ALVES, J. Jerônimo de Alencar.

A ciência pura e a Academia Brasileira de Ciências. In: Quipu: Revista Latinoamericana de Historia de las Ciências y la Tecnologia, Ciudad de México, v.8, n.1, p.111-122. 1991.

BATES, Henry Walter.

Um naturalista no rio Amazonas. Belo Horizonte: Itatiaia. 1979.

BERRY, Andrew.

Infinite tropics: an Alfred Russel Wallace antology. London: Verso. 2003.

BOURDIEU, Pierre.

Os usos sociais da ciência. São Paulo: Unesp. 1997.
CRISPINO, Luis Carlos Bassalo.

As origens do Museu Paraense Emílio Goeldi: aspectos históricos e iconográficos, 1860-1921. Belém: Paka-Tatu. 2006.

EDWARDS, William.

A voyage up the river Amazon: including a residence at Pará. New York: Cornell University Library. 1847.

FERREIRA, Ricardo.

Bates, Darwin, Wallace e a teoria da evolução. Brasília: Editora da UnB. 1990.

FOUCAULT, Michel.

As palavras e as coisas. São Paulo: Martins Fontes. 1987.

FOUCAULT, Michel.

A arqueologia do saber. Rio de Janeiro: ForenseUniversitária. 1986.

GEERTZ, Clifford.

A interpretação das culturas. Rio de Janeiro: Livros Técnicos e Científicos. 1989.

KUHN, Thomas.

A estrutura das revoluções científicas. São Paulo: Perspectiva. 1987. 
KURY, Lorelai.

Viajantes naturalistas no Brasil oitocentista: experiência, relato e imagem. História, Ciências, Saúde - Manguinhos, v.8, suplemento, p.863880. 2001.

LATOUR, Bruno.

Jamais fomos modernos. Rio de Janeiro: Editora 34. 1994.

POLANCO, Xavier.

Une science-monde: la mondialization de la science européene et la creation de traditions scientifiques. In: Polanco, Xavier (Org.).

Naissance et développement de la science-monde: production et reproduction des communautés scientifiques en Europe et en Amerique Latine. Paris: La Découverte; Conseil de l'Europe; Unesco. p.10-52. 1989.
PESTRE, Dominique.

Physique et phisiciens en France, 1918-1940. Paris: Editions des Archives Contemporaines. 1985.

SANJAD, Nelson.

A Coruja de Minerva: o Museu Paraense entre o Império e a República, 1866-1907. Rio de Janeiro: Editora da Fiocruz. 2010.

VENTURA, Roberto.

Estilo tropical. São Paulo: Companhia das Letras. 1991.

WALLACE, Alfred Russel.

Viagens pelos rios Amazonas e Negro. Belo Horizonte: Itatiaia. 1979. 